\title{
Additive Manufacturing and Performance of E-Type Transformer Core
}

\author{
Hans Tiismus ${ }^{1, *(\mathbb{D})}$, Ants Kallaste ${ }^{1} \mathbb{D}$, Anouar Belahcen ${ }^{2} \mathbb{D}$, Anton Rassolkin ${ }^{1} \mathbb{D}$, Toomas Vaimann ${ }^{1} \mathbb{D}$ \\ and Payam Shams Ghahfarokhi 1,3 (D)
}

1 Institute of Electrical Power Engineering and Mechatronics, Tallinn University of Technology, 19086 Tallinn, Estonia; ants.kallaste@taltech.ee (A.K.); anton.rassolkin@taltech.ee (A.R.); toomas.vaimann@taltech.ee (T.V.); payam.shams@taltech.ee (P.S.G.)

2 Department of Electrical Engineering and Automation, Aalto University, 02150 Espoo, Finland; Anouar.Belahcen@aalto.fi

3 Department of Electrical Machines and Apparatus, Riga Technical University, Kalku iela 1, LV-1658 Riga, Latvia

* Correspondence: hans.tiismus@taltech.ee

Citation: Tiismus, H.; Kallaste, A.; Belahcen, A.; Rassolkin, A.; Vaimann, T.; Shams Ghahfarokhi, P. Additive Manufacturing and Performance of E-Type Transformer Core. Energies 2021, 14, 3278. https://doi.org/ $10.3390 /$ en14113278

Academic Editor:

Salvatore Musumeci

Received: 5 May 2021

Accepted: 31 May 2021

Published: 3 June 2021

Publisher's Note: MDPI stays neutral with regard to jurisdictional claims in published maps and institutional affiliations.

Copyright: (c) 2021 by the authors. Licensee MDPI, Basel, Switzerland. This article is an open access article distributed under the terms and conditions of the Creative Commons Attribution (CC BY) license (https:/ / creativecommons.org/licenses/by/ $4.0 /)$.

\begin{abstract}
Additive manufacturing of ferromagnetic materials for electrical machine applications is maturing. In this work, a full E-type transformer core is printed, characterized, and compared in terms of performance with a conventional Goss textured core. For facilitating a modular winding and eddy current loss reduction, the 3D printed core is assembled from four novel interlocking components, which structurally imitate the E-type core laminations. Both cores are compared at approximately their respective optimal working conditions, at identical magnetizing currents. Due to the superior magnetic properties of the Goss sheet conventional transformer core, $10 \%$ reduced efficiency (from $80.5 \%$ to $70.1 \%$ ) and $34 \%$ lower power density (from $59 \mathrm{VA} / \mathrm{kg}$ to $39 \mathrm{VA} / \mathrm{kg}$ ) of the printed transformer are identified at operating temperature. The first prototype transformer core demonstrates the state of the art and initial optimization step for further development of additively manufactured soft ferromagnetic components. Further optimization of both the 3D printed material and core design are proposed for obtaining higher electrical performance for AC applications.
\end{abstract}

Keywords: additive manufacturing; soft magnetic materials; selective laser melting; iron losses; magnetic properties; transformer

\section{Introduction}

Metal additive manufacturing (AM) is maturing, enabling previously unavailable production possibilities in terms of feasible product complexity and personalization. As currently, the cost per part of AM is still relatively high, it has been most applicable for parts for high tech industries: producing specialized parts benefiting the most from the topology optimization possibilities of AM. For example, 3D printing has been utilized for the production of more efficient and long-lasting inductor coils [1], stronger, cheaper and lighter aircraft fuel nozzles [2], and high performance heat exchangers [3].

In parallel to the printing of structural, thermal, and electrical components, research interest in printed soft magnetic materials and topology optimized electromechanical components has spiked drastically over recent years. It has been proposed that with the easily available computational power and free-form printing capabilities of AM systems, next generation electrical machine designs could be modelled and constructed by the research community. These topology optimized designs (with reduced weight, integrated cooling channels, reduced inertia, increased heat exchange etc.) could be prototyped in-house, significantly reducing the lead time, cost, and machinery involved [4].

State of the art additive manufacturing of electromagnetic devices involves selective laser melting (SLM) printing of conductive and soft magnetic materials with air gaps 
partitioning the material structure for separating individual turns in coils and reducing the induced eddy currents in soft magnetic cores $[5,6]$. The air gaps are printed due to the current lack of multi-material printing capacity of SLM systems, limiting the parallel printing of conductive, core, and insulation materials. The introduction of airgaps considerably reduces the power density of the components, however, as gapped printed component fill factor is typically relatively low (in the range of 60\%) [6,7].

Despite extensive material optimization of different soft magnetic alloys, relatively few functional components or devices have actually been printed and characterized. For this reason, in this work, a full small-scale transformer core is printed, characterized, and compared with a commercial transformer. The simplistic design of an E-type transformer makes it ideal for the next step of testing additively manufactured magnetic material capacity and performance for electrical machine applications (succeeding the characterization of small-scale toroidal samples). In this paper, a novel interlocking core design is employed for eddy current reduction, which exhibits a competitive component fill factor. The paper is divided into two larger sections. The first part describes the 3D printed core design and its fabrication process, and the second the characterization and comparison of the printed core with conventional cores.

\section{Transformer Core Design}

\subsection{Commercial Transformer}

The 3D printed core design investigated in this paper was based on the commercially available 30 VA single phase isolation transformer provided by MS Balti Transformers Ltd (Tallinn, Estonia). The transformer was chosen based on its suitable size, type, and availability. Its shell-type transformer core is constructed from E-type stampings of grainoriented M 165-35S silicon steel. The conventional transformer design with its dimensions are detailed on Figure 1.
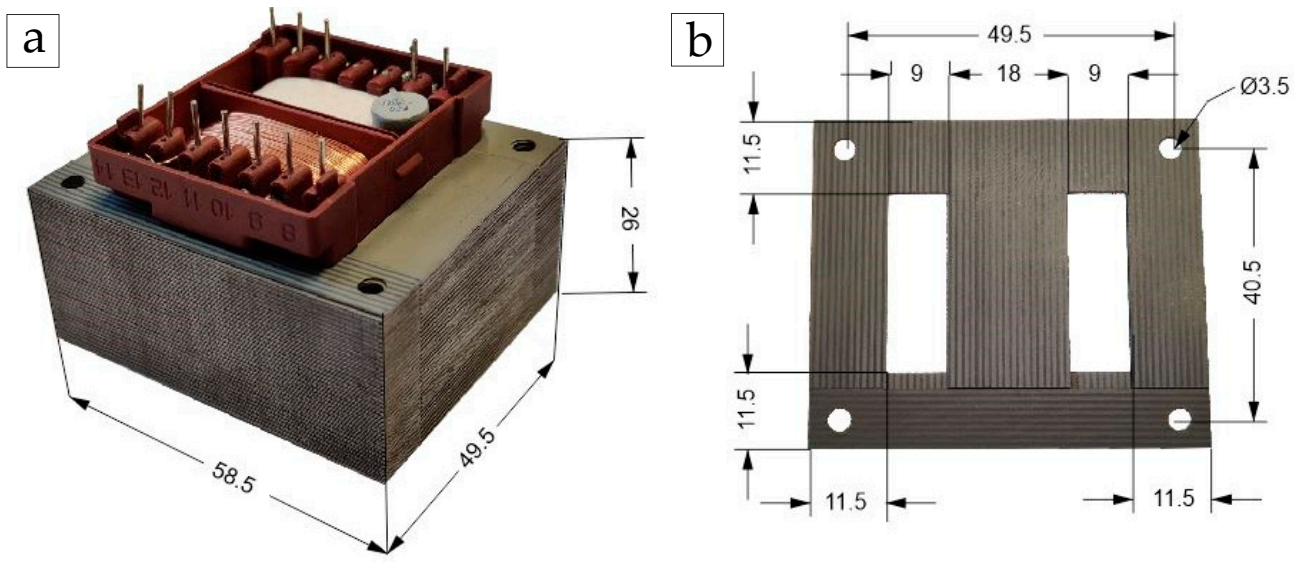

Figure 1. Investigated conventional transformer: (a) Core dimensions, (b) E-type stamping dimensions in detail.

The fully encapsulated modular windings of the transformer are utilized in both the conventional and 3D printed core designs. The modular windings are incorporated in both designs in order to improve the comparability of the transformer core performance and to demonstrate the compatibility of 3D printed and conventional parts. The nominal parameters of the windings are characterized in Table 1.

\subsection{D Printed Design}

Next, an SLM printing system was utilized for the 3D printing of the full transformer core. The 3D printed core design was required to exhibit compatibility with the modular windings, incorporate the segregated structure for classical eddy current loss reduction with high filling factor, and adhere to the printing system requirements. Lamination thickness of 
$0.95 \mathrm{~mm}$ was chosen to obtain high fill factor and mechanical strength of the first prototype. For all segregated designs considered, it was critical to achieve continuous geometries (with minimal air gaps dividing the flux paths) with maximal flux path cross sectional area (high fill factor). Furthermore, since the printed transformer must be comprised of at least two parts (to accommodate the modular winding), optimization of the inter-part air gap must be considered. In conventional transformers, the influence of the inter-stamping airgaps is typically reduced by overlapping stamping layers: which facilitates the flux paths through the adjoining stampings. Similar overlap between the flux-guides can be realized in printed designs.

Table 1. Nominal parameters of the modular transformer coil.

\begin{tabular}{cccccc}
\hline Winding & Turns & $\begin{array}{c}\text { Resistance } \\
(\boldsymbol{\Omega})\end{array}$ & $\begin{array}{c}\text { Nominal } \\
\text { Voltage (V) }\end{array}$ & $\begin{array}{c}\text { Nominal } \\
\text { Current (A) }\end{array}$ & $\begin{array}{c}\text { Insulation } \\
\text { Class }\end{array}$ \\
\hline Primary & 1370 & 98 & 230 & 0.17 & $\mathrm{H}$ \\
Secondary 1 & 151 & 1.35 & 25.1 & 1.3 & $\mathrm{~F}$ \\
Secondary 2 & 56 & 2.7 & 9.3 & 0.25 & $\mathrm{~F}$ \\
\hline
\end{tabular}

For simplicity, in this paper, only conventional stamping inspired designs were considered for 3D printing. In Figure 2, three considered transformer core designs are illustrated: (a) a laterally laminated interlocking design from four parts, (b) an axially laminated gapped design from two parts, and (c) an axially laminated interlocking design from four parts. The axially laminated interlocking design was chosen for printing due to its simplicity and similarity to the conventional design, its high achievable fill factor and its post-processing possibilities: all of the unmelted powder can be removed between the laminations post-printing and, if needed, all of the surfaces can be cleaned and oxidized or varnished for enhanced inter-lamination electrical resistance.

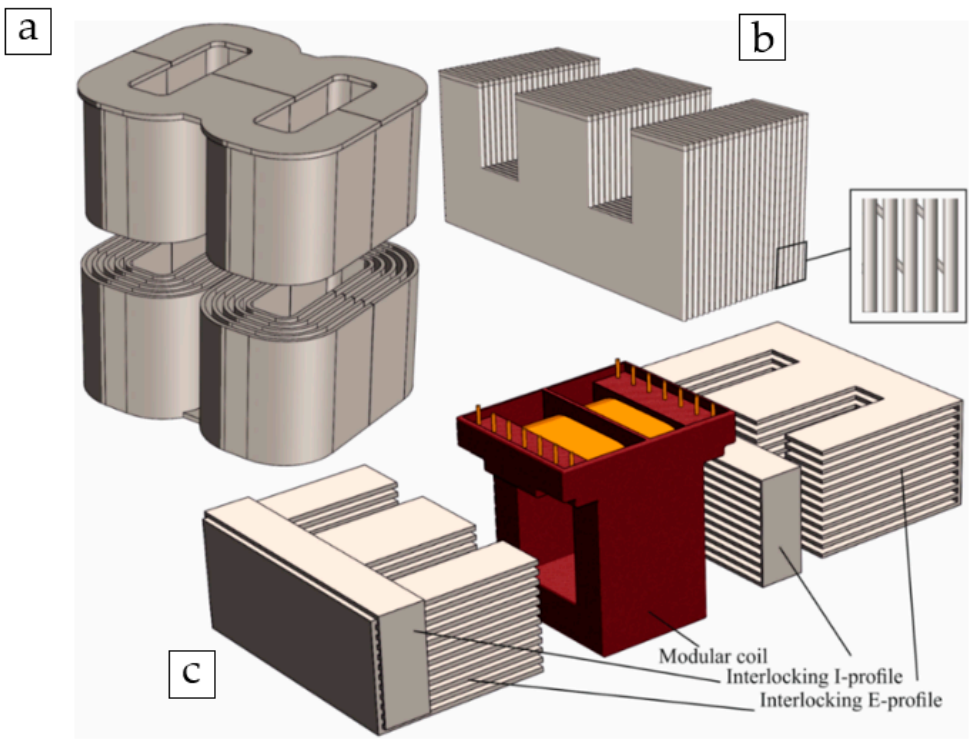

Figure 2. Considered lamination strategies: (a) Laterally laminated interlocking design, (b) Axially laminated design with air-gapped core structure, (c) Exploded view of the 3D printed transformer core design with interlocking axial laminations comprising four individual components.

\section{Methods}

\subsection{Powder Characteristics}

Transformer parts were printed with identical powder, processing, and annealing parameters to the previous study characterizing the AC and DC losses of the printed material [6]. Pre-alloyed, gas-atomized Fe-Si provided by Sandvik group was utilized for printing. The powder exhibited roughly spherical particle shape with a median diameter 
of $38 \mu \mathrm{m}$, and its chemical composition is described in Table 2. The powder size, shape, and chemical composition were verified to verify the manufacturer declaration.

Table 2. Chemical composition of the employed Fe-Si powder.

\begin{tabular}{ccccccc}
\hline Elements & Fe & Si & Mn & Cr & Ni & C \\
\hline $\mathrm{Wt} \%$ & Balance & 3.7 & 0.2 & 0.16 & 0.020 & 0.01 \\
\hline
\end{tabular}

\subsection{SLM Printing of the Transformer Core}

Transformer core parts were printed on the SLM Solutions GmbH Realizer SLM-280. The printing system provides a $280 \times 280 \times 350$ maximum build envelope and a single $1070 \mathrm{~nm}$ yttrium scanning laser $(1 \times 700 \mathrm{~W})$. Custom smaller build platform $(\mathrm{D} 100 \mathrm{~mm})$ and re-coater were used for printing of the transformer core, designed for streamlining the powder substitution between projects for different raw powders.

Laser re-melting strategy was used to prevent the powder balling related uneven growth of the relatively large transformer parts during printing, which can result in rough porous material structure or the termination of the print job due to re-coater jamming. The phenomenon is related to an oxide film on the preceding layer impeding interlayer bonding and leading to balling, due to insufficient wetting of the molten metal on the oxide layer [8]. The balling phenomenon can be reduced in a higher purity environment (oxygen level below $0.1 \%$ ), applying a combination of high laser powder and low scanning rate or applying re-melting scanning on the part [9].

Stripe $\left(10 \mathrm{~mm}\right.$ wide) scan pattern was utilized with $30^{\circ}$ rotation between layers. All of the printing was conducted in a nitrogen inert gas environment because of its relatively low cost. Platform pre-heating was not utilized as the custom reduced platform is not equipped for it. A summary of the main laser printing parameters is presented in Table 3.

Table 3. Summary of the printing parameters.

\begin{tabular}{cc}
\hline Parameter & Value \\
\hline Layer thickness & $50 \mu \mathrm{m}$ \\
Hatch distance & $120 \mu \mathrm{m}$ \\
Laser Power & $250 \mathrm{~W}$ (primary) $/ 100 \mathrm{~W}$ (secondary) \\
Scanning velocity & $0.5 \mathrm{~m} / \mathrm{s}$ (primary) $/ 0.5 \mathrm{~m} / \mathrm{s}$ (secondary) \\
Scan strategy & Stripes \\
Environment & Nitrogen \\
Oxygen content & $\sim 0.1 \%$ \\
\hline
\end{tabular}

Transformer printing was completed in three parts in a total of $16 \mathrm{~h}$ : interlocking E-profiles separately $(2 \times 6 \mathrm{~h})$ and the I-profiles in the same build $(1 \times 4 \mathrm{~h})$. The printed components are illustrated in Figure 3: showing the surface finish, support structure, and the powder bed post-printing. Some concave warpage of the E-profiles was observed after separation from the build platform due to internal part stress, which obstructed the transformer assembly. Its causality can be traced to the relatively high internal stresses induced in part by the micro-welding process of SLM, and it can be resolved through the annealing of the printed parts at moderate temperature, pre-cutting from the platform for stress relief. Next, the support surfaces were polished and the inter-lamination air-gaps were lightly sanded for improved surface finish and fitting of the components. 


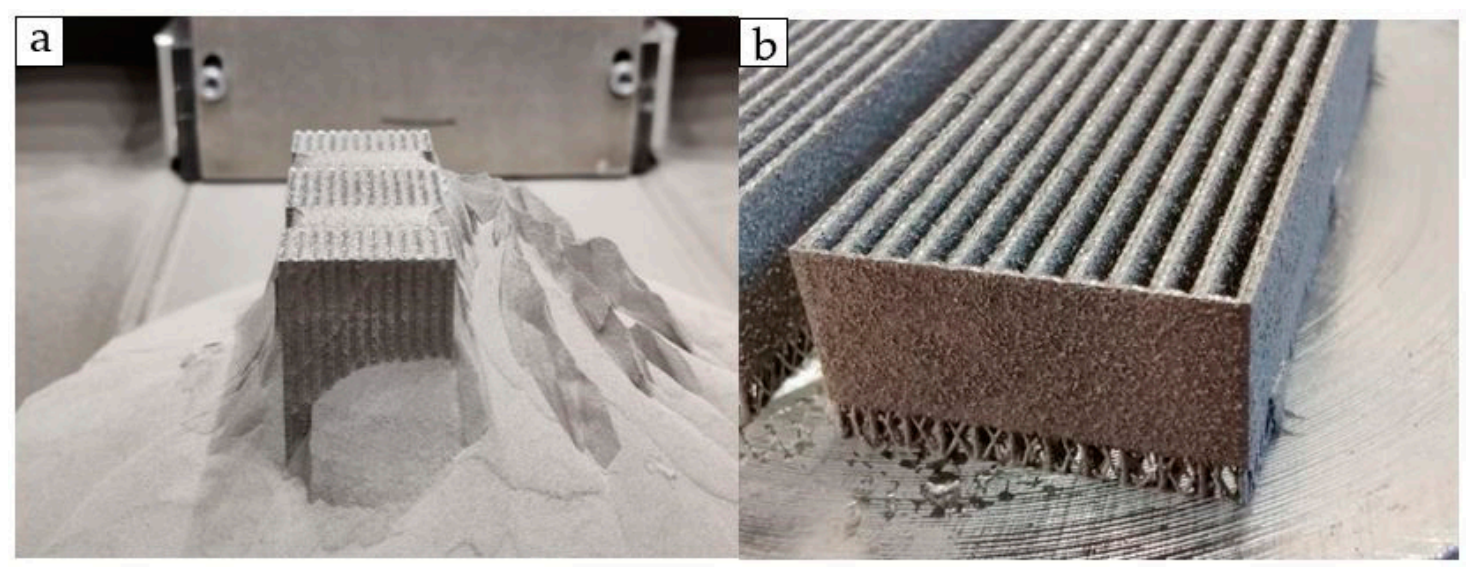

Figure 3. SLM printed transformer components: (a) E-profile component post-printing, (b) I-profile component welded on the baseplate.

\subsection{Annealing}

After mechanical post-processing, the printed transformer parts were annealed at $1200{ }^{\circ} \mathrm{C}$ in a low vacuum environment $(\sim 0.1 \mathrm{mBar})$ with a heating rate of $300 \mathrm{~K} / \mathrm{h}$, maintained at the target temperature for $1 \mathrm{~h}$ and then slowly furnace-cooled to room temperature.

\subsection{Material Properties}

The additively manufactured $3.7 \%$ silicon steel shows comparable magnetic performance to non-oriented conventional silicon steels after thermal treatment. Magnetization of $1.5 \mathrm{~T}$ is achieved at $1800 \mathrm{~A} / \mathrm{m}$, exhibiting electrical resistivity of $56.9 \mu \Omega \cdot \mathrm{cm}$ and hysteresis losses of $0.61\left(\mathrm{~W}_{10,50}\right)$ and $1.7\left(\mathrm{~W}_{15,50}\right) \mathrm{W} / \mathrm{kg}$ [6]. In comparison, a typical non-oriented steel M235-35A used for electrical machine fabrication exhibits total core losses of $0.92\left(\mathrm{~W}_{10,50}\right)$ and $2.35 \mathrm{~W} / \mathrm{kg}\left(\mathrm{W}_{16,50}\right)$, resistivity of $59 \mu \Omega \cdot \mathrm{cm}$, and magnetization of $1.53 \mathrm{~T}$ at $2500 \mathrm{~A} / \mathrm{m}$. In this paper, we are comparing the additively manufactured core with a conventional Goss textured silicon steel M165-35S (equivalent to M111-35N) core, which shows superior magnetic properties to the non-oriented materials for transformer applications, as presented on Figure 4. The grain-oriented transformer steel shows approximately $0.3 \mathrm{~T}$ greater saturation magnetization than both of the non-oriented steels.

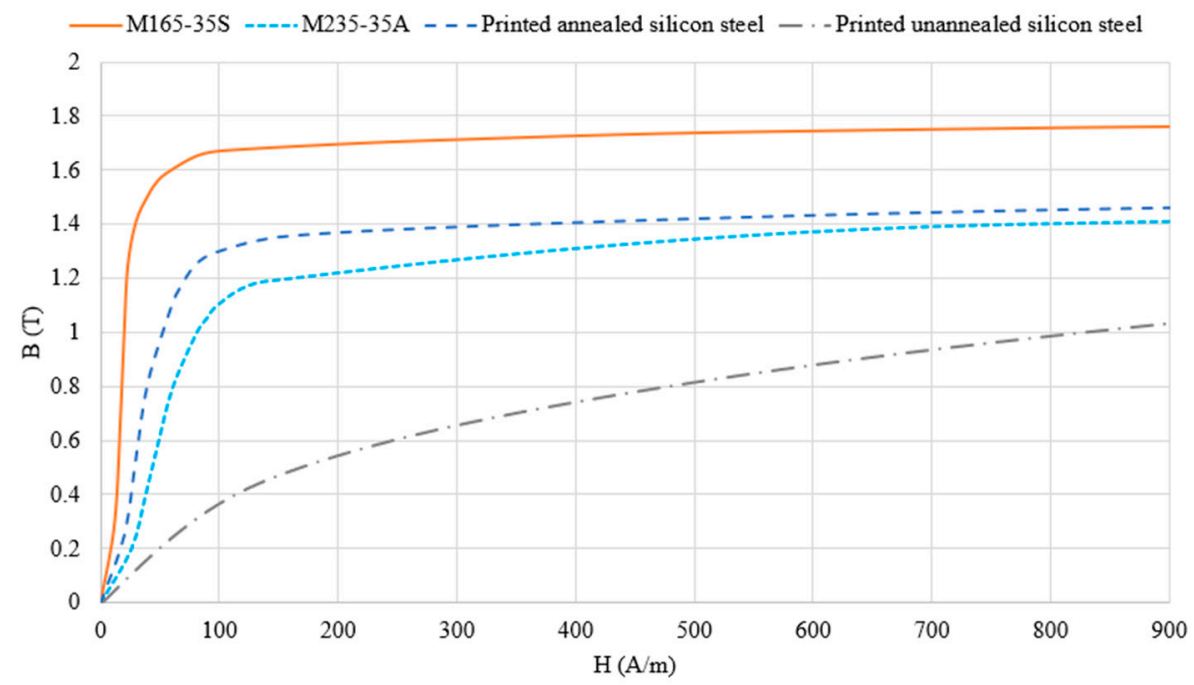

Figure 4. Magnetization curves of the studied materials: grain-oriented silicon steel M165-35S [10,11], non-oriented silicon steel M235-35A [12], printed annealed 3.7\% silicon steel, and printed unannealed $3.7 \%$ silicon steel [6]. 
The grade designation of M165-35S of the Goss textured steel specifies $1.65 \mathrm{~W} / \mathrm{kg}$ losses at $1.7 \mathrm{~T}\left(\mathrm{~W}_{17,50}\right)$, and a lamination thickness of $0.35 \mathrm{~mm}$. The materials' exact silicon content, resistivity, and other typical properties are unspecified and depend on the manufacturer (manufacturing freedom in the range of grade specifications).

\subsection{Transformer Characterization}

The nominal performances of both the 3D printed and the conventional magnetic core transformers were characterized through open circuit and full load testing. The nominal parameters of the conventional transformer were obtained from the manufacturer's declaration. A drop in the nominal voltage is expected for the printed transformer due to its reduced fill factor, possible fitting defects (air-gaps between laminations), and lower saturation magnetization of the printed material. Its nominal voltage and iron losses were determined from the open circuit tests of the conventional transformer. To determine the transformer efficiencies, a load test was performed, where the transformer was energized up to nominal power. For thermal performance assessment, steady-state thermal images of the fully loaded transformers were captured with a Fluke Ti10 Thermal Camera.

The open circuit test setup is described in Figure 5, consisting of an autotransformer for variable voltage input and digital multimeters for measuring the voltage, current, and active power consumed in the transformer coil. In the open circuit test, the current drawn by the transformer establishes the magnetic field in the core. The active power consumed by the transformer signifies its total power loss, consisting mainly of magnetizing, and some ohmic, losses. The magnetizing losses summarize the energy lost from each magnetizing cycle, which are classically segregated into the hysteresis, classical, and excess eddy current loss.
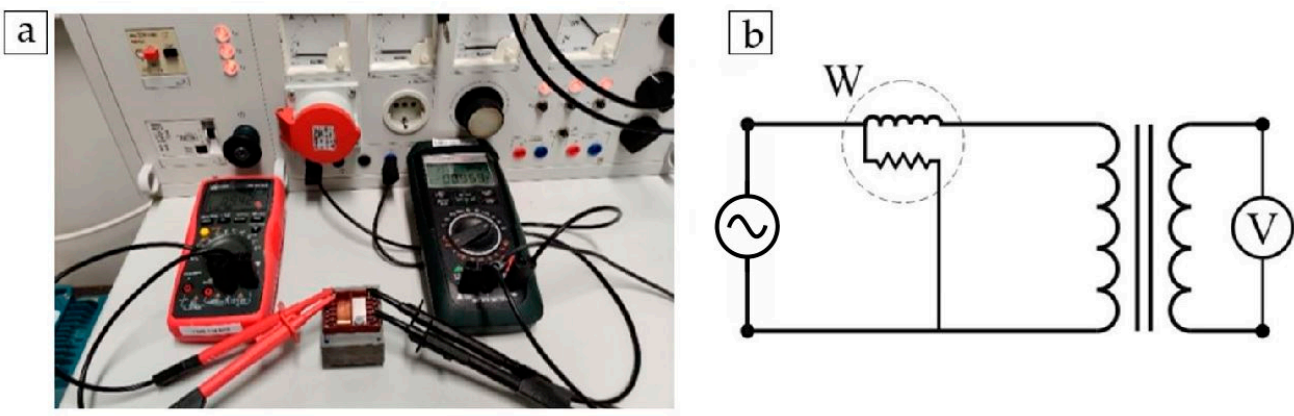

Figure 5. Open circuit transformer: test setup (a) and its schematic (b).

The ohmic losses are induced from joule heating of the coils due to the magnetizing current drawn. The total specific transformer core losses can be calculated from (1), where $W$ is the active power loss measured in the open circuit test, $I$ is the magnetizing current, $R$ is the magnetizing coil resistance, and $m$ is the weight of the core.

$$
P=\frac{\left(W-I R^{2}\right)}{m}
$$

Traditionally, the magnetic material loss behaviour is discussed in terms of cycle peak polarization $\left(B_{\max }\right)$ of the core. Unlike in the toroidal cores for magnetic material characterization $[6,13]$, however, the flux density in the investigated transformer core can only be evaluated as an approximation, due to its uneven flux distribution. The analytical expression for calculating the peak polarization in a transformer can be derived from the differential form of Faraday's law (2), where $E$ is the induced electromotive force by the switching magnetic field, $N$ is the number of turns on the primary coil (1370), $f$ is the excitation frequency of the magnetic field $(50 \mathrm{~Hz}), B_{\max }$ is the peak material polarization, $S$ is the core cross sectional area, $F$ is the core filling factor, $U$ is the applied voltage on the primary coil, and $U_{r}$ is the voltage drop over the primary coil. 


$$
E=N \frac{d \Phi}{d t} \rightarrow E_{\max }=N 2 \pi f S F B_{\max } \rightarrow B_{\max }=\frac{E_{\max }}{N 2 \pi f S F}=\frac{U-U_{r}}{N 2 \pi f S F}
$$

Alternatively, the approximate material polarization can be evaluated from the material B-H curve (as presented on Figure 4) or by the finite element method (FEM) simulation. In both methods, the actual B-H curve of the transformer core can differ from the previously characterized material, most prominently due to air-gap related curve shearing. For $B_{\max }$ evaluation, the magnetic field strength in the transformer is calculated from (3), where $N$ is the number of turns on the primary coil, $i$ is the peak magnetizing current and $l$ is the length of the mean magnetic flux path of the core. All FEM simulations are performed in open source finite element analysis software package Finite Element Method Magnetics (FEMM). The model accounts for the transformer cross sectional geometry, magnetized up to the peak magnetizing current measured from the open circuit test, including the material magnetization curve and fill factor, but excluding any gaps in the core internal structure.

$$
H=\frac{N i}{l}
$$

\section{Results}

\subsection{Assembled Transformer}

The conventional and finished assembled printed transformer cores are presented in Figure 6. The overall transformer core dimensions correlated well, with the printed transformer exhibiting a slightly thinner and lighter core. The fill factor of the 3D printed core was measured from the axial centerline of the interlocking E-cores. For the conventional transformer, the fill factor was adopted from the stamping datasheets. The physical comparison of the transformer cores is presented in Table 4. No additional oxidation, treatment, or varnishing was applied to the surfaces of the 3D printed transformer core for increased eddy current reduction - the insulation is provided by the high natural surface roughness of the printed parts.

a

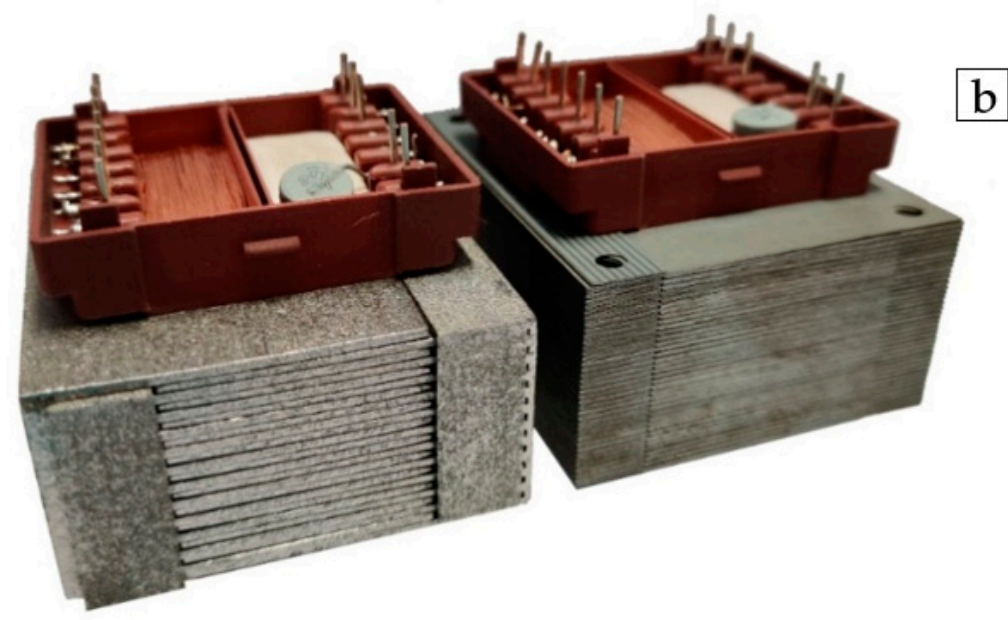

Figure 6. Printed (a) and conventional (b) transformer cores.

Table 4. Physical comparison of the transformer cores.

\begin{tabular}{ccccccc}
\hline Core & $\begin{array}{c}\text { Lamination } \\
\text { Thickness }(\mathrm{mm})\end{array}$ & Fill Factor & Dimensions $(\mathbf{m m})$ & $\begin{array}{c}\text { Weight } \\
\text { Core } \mathbf{( k g})\end{array}$ & $\begin{array}{c}\text { Weight } \\
\text { Coil (kg) }\end{array}$ & Varnish \\
\hline $\begin{array}{c}\text { Conventional } \\
\text { Printed }\end{array}$ & 0.35 & 0.96 & $58.5 \times 49.8 \times 26.0$ & 0.44 & 0.095 & Yes \\
\hline
\end{tabular}

\subsection{Performance}

Open circuit tests of the transformers confirmed the flux drop in the core and the reduction of the sustainable operating voltage of the printed transformer. In Figure 7, both 
the magnetizing current drawn from the supply for generating the desired voltage and the iron loss behavior calculated from (1) are presented. At $40 \mathrm{~mA}$ magnetizing current, the conventional transformer is energized up to $230 \mathrm{~V}$, while the printed transformer is energized to a $30 \%$ lower voltage of $160 \mathrm{~V}$. This is due to the lower flux density sustained by the printed material. For energizing the printed transformer up to $230 \mathrm{~V}$, a magnetizing current of $220 \mathrm{~mA}$ is required. This is inefficient, however, due to deep core oversaturation, requiring $450 \%$ more current than for magnetizing the conventional core and $30 \%$ more current than the rated full load current of the winding.

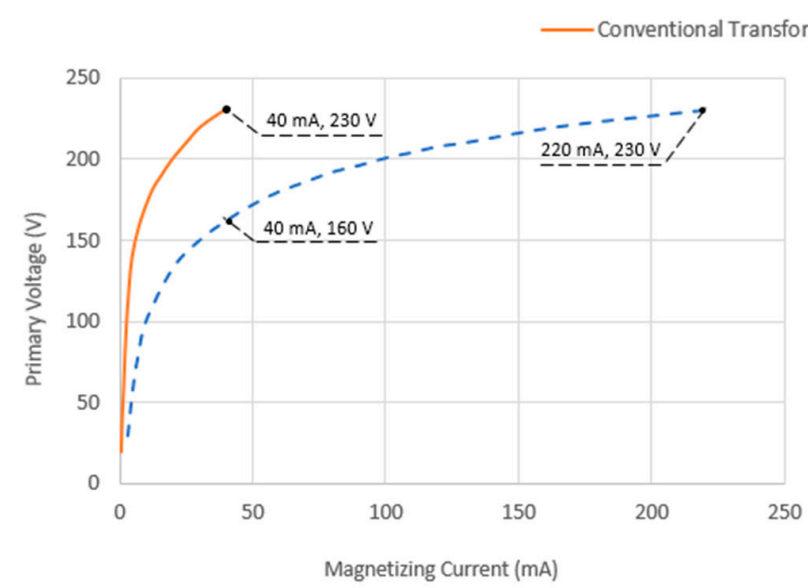

(a)

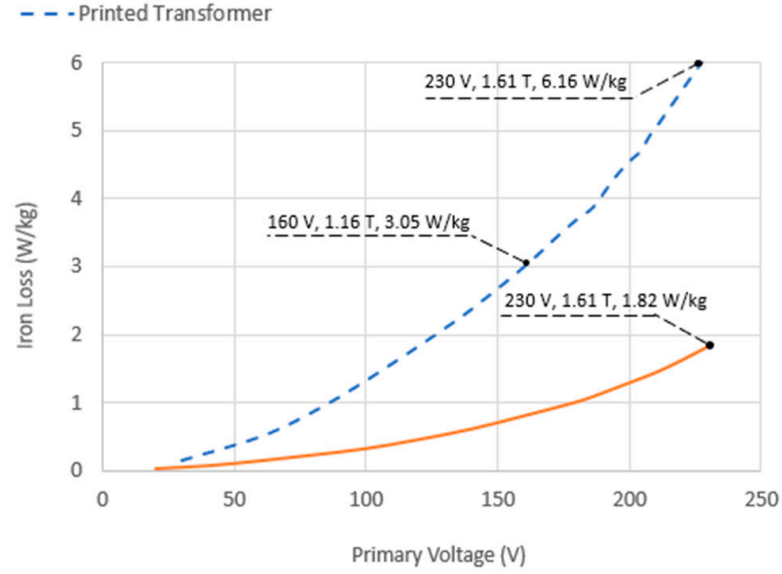

(b)

Figure 7. Magnetizing current drawn (a) and the specific core loss (b) of the tested transformers.

At $40 \mathrm{~mA}$ RMS excitation current (60 mA peak current), the analytically calculated (3) average $\mathrm{H}$ field generated in the magnetic core is $668 \mathrm{~A} / \mathrm{m}$, which corresponds to the magnetization of $1.72 \mathrm{~T}$ for M165-35S and $1.42 \mathrm{~T}$ for the annealed 3D printed material as determined from the magnetization curves in Figure 8. At $40 \mathrm{~mA}$ RMS excitation current, analogous excitation of both cores is achieved. Both are magnetized slightly above the approximate material knee-point and exhibit identical copper losses. Excitation of the conventional core to $160 \mathrm{~V}$ or the $3 \mathrm{D}$ printed core to $230 \mathrm{~V}$ would be impractical comparison-wise, as both states exhibit significantly differing magnetic behavior. At $160 \mathrm{~V}$, the conventional core is still at the linear magnetic behavior: drawing only $7.6 \mathrm{~mA}$ magnetizing current and exhibiting $0.005 \mathrm{~W}$ of copper losses and $0.35 \mathrm{~W}$ of iron losses. At $230 \mathrm{~V}$, the printed transformer shows deep saturation behavior, drawing $220 \mathrm{~mA}$ of magnetizing current, resulting in a significant voltage drop of $21.6 \mathrm{~V}$, copper losses of $4.7 \mathrm{~W}$, and iron losses of $2.6 \mathrm{~W}$.
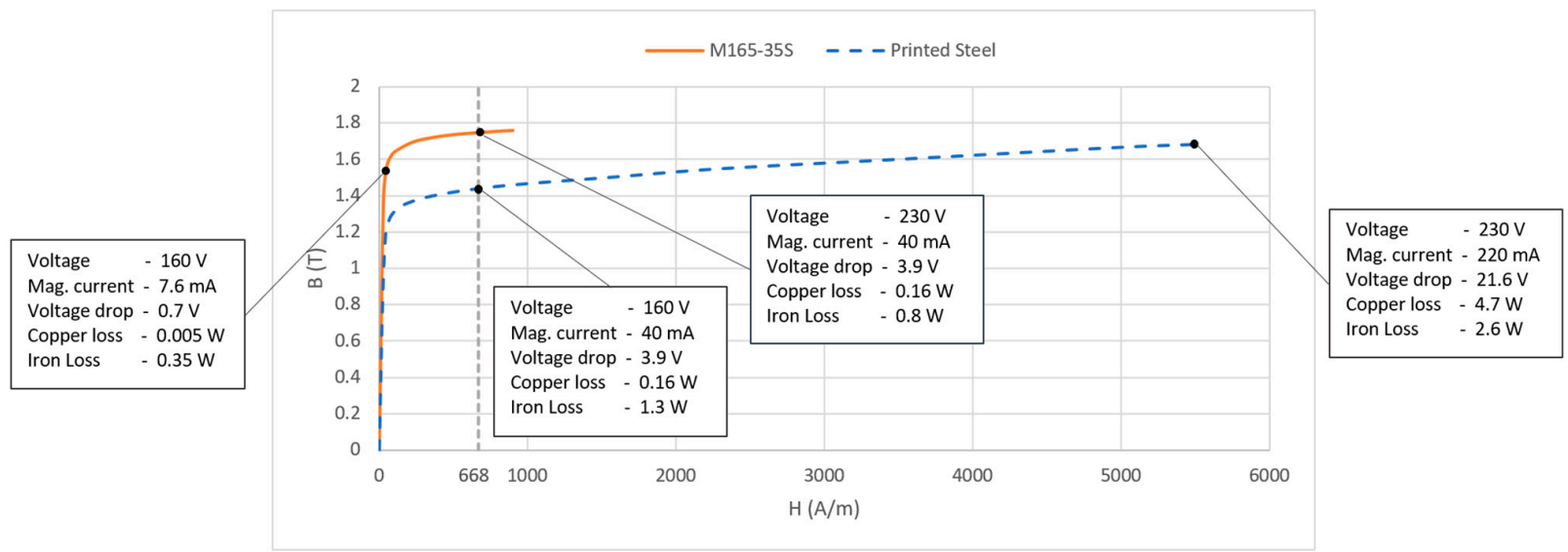

Figure 8. Core material magnetization curves correlated with the no load measurements of the investigated transformers. 
FEM simulation of the transformer cores shows similar values of material magnetization: reaching $1.68 \mathrm{~T}$ for the conventional and 1.39 for the 3D printed core (Figure 9). Additionally, the simulation illustrates the uneven flux distribution in the core due to variations in transformer limb width. Analytical calculations with (2) show lower core flux density required for inducing a specific voltage in the core. For energizing the transformer up to $230 \mathrm{~V}$, a flux density of $1.65 \mathrm{~T}$ is required, while for $160 \mathrm{~V}$, a flux density of $1.26 \mathrm{~T}$ is required. The higher magnetization calculated from the experimental excitation current and FEM simulation is most likely the result of intra-lamination air-gaps, which shears the material magnetization curve and requires more current for achieving the same material polarization.

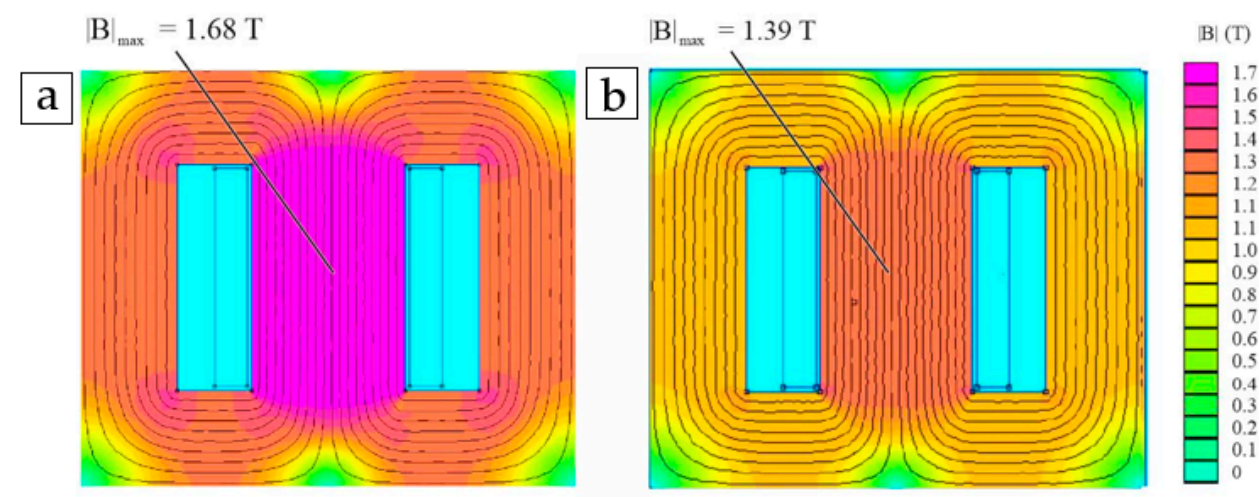

Figure 9. Flux distribution in the (a) conventional and (b) 3D printed transformer core.

Iron losses were identified as $1.82 \mathrm{~W} / \mathrm{kg}$ for the conventional core at $230 \mathrm{~V}$ (at approximately $1.7 \mathrm{~T}, 50 \mathrm{~Hz}$ ) and $3.05 \mathrm{~W} / \mathrm{kg}$ for the $3 \mathrm{D}$ printed core at $160 \mathrm{~V}$ (in the range of 1.26-1.4 T, $50 \mathrm{~Hz}$ ). Efficiency of the transformers was calculated from the load test measurements at both the ambient core temperature and the steady state temperature at full load conditions. The transformers reached steady state temperature after four hours of loading. The thermal images of the transformers are shown in Figure 10, with slightly higher heating observed for the 3D printed transformer core. The measured coil hotspot temperature was measured at $91.1^{\circ} \mathrm{C}$ for the conventional core and at $95.1{ }^{\circ} \mathrm{C}$ for the $3 \mathrm{D}$ printed core. The core hotspots were measured with a thermocouple sensor due to the high reflectivity of the printed core, exhibiting temperatures of $71^{\circ} \mathrm{C}$ (conventional) and $75{ }^{\circ} \mathrm{C}$ (3D printed).

At full load, the measured efficiency of the transformers ranged from $83.8 \%\left(21^{\circ} \mathrm{C}\right)$ to $80.4 \%\left(71^{\circ} \mathrm{C}\right)$ for the conventional transformer and $74.7 \%\left(21^{\circ} \mathrm{C}\right)$ to $70.1 \%\left(75^{\circ} \mathrm{C}\right)$ for the $3 \mathrm{D}$ printed transformer. The efficiency-load characteristic is presented in Figure 11. The highest efficiencies were measured at $41 \%$ load at ambient core temperature, reaching an efficiency of $88.7 \%$ for the conventional transformer and $80.5 \%$ for the 3D printed core. The efficiency of the 3D printed core was approximately $10 \%$ lower over the full measurement range. Due to the material saturation and inter-lamination air-gap related reduction of nominal voltage, the printed transformer core sustained reduced power density when compared to the conventional core. The transformer power density dropped $34 \%$ from $59 \mathrm{~W} / \mathrm{kg}$ to $39 \mathrm{~W} / \mathrm{kg}$. The results of the transformer performance characterization are summarized in Table 5. 


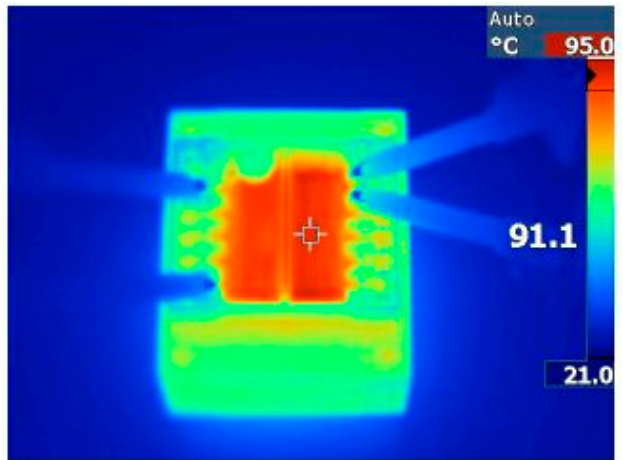

(a)

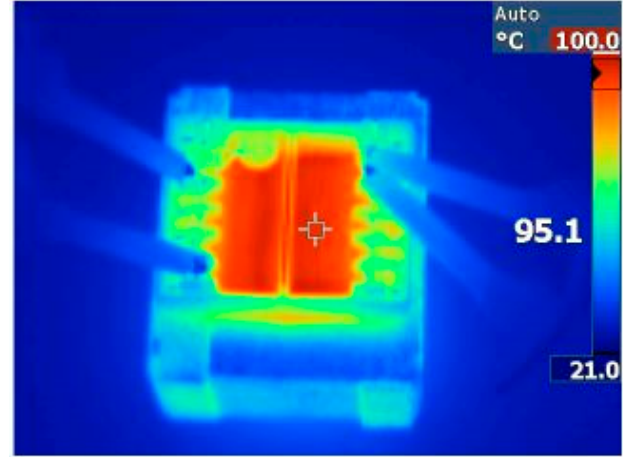

(b)

Figure 10. Steady state temperature of the studied transformers in the (a) conventional core and (b) 3D printed transformer core.

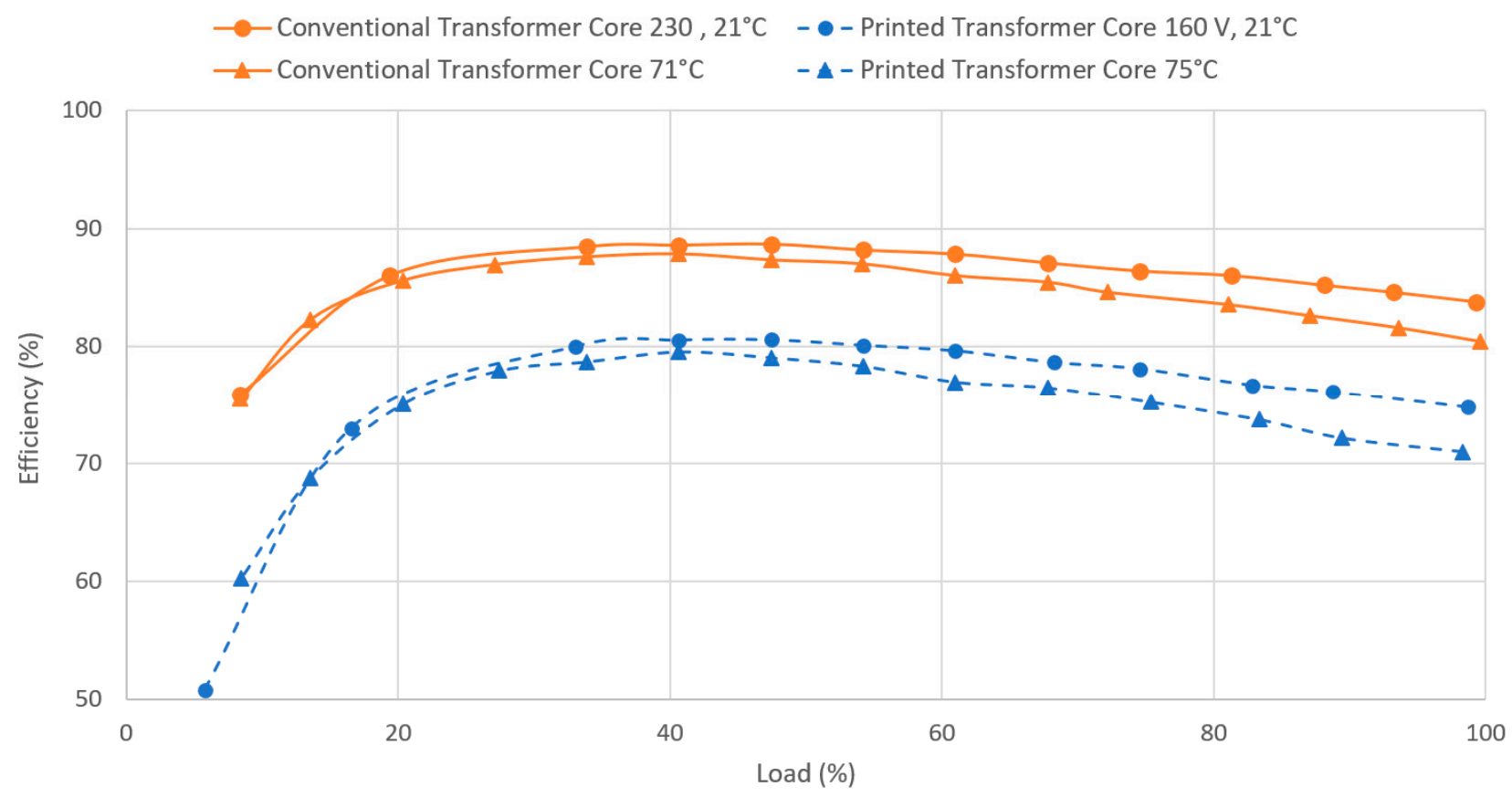

Figure 11. Efficiency-load characteristics of the studied transformers.

Table 5. Comparison of transformer performance.

\begin{tabular}{ccc}
\hline Parameter (Full Load, $\left.\mathbf{2 1}^{\circ} \mathbf{C}\right)$ & 3D Printed Core & Conventional Core \\
\hline Nominal Voltage & $160 \mathrm{~V}$ & $230 \mathrm{~V}$ \\
Nominal Current & $0.17 \mathrm{~A}$ & $0.17 \mathrm{~A}$ \\
Power Factor & 0.97 & 0.97 \\
Input Power & $27.2 \mathrm{VA}$ & $39.1 \mathrm{VA}$ \\
Output power & $19.8 \mathrm{VA}$ & $31.8 \mathrm{VA}$ \\
Efficiency (ambient temperature) & $74.7 \%$ & $83.8 \%$ \\
Efficiency (operating temperature) & $70.1 \%$ & $80.5 \%$ \\
Power Density (Core) & $47 \mathrm{VA} / \mathrm{kg}$ & $72 \mathrm{VA} / \mathrm{kg}$ \\
Power Density (Full Transformer) & $39 \mathrm{VA} / \mathrm{kg}$ & $59 \mathrm{VA} / \mathrm{kg}$ \\
\hline
\end{tabular}

\section{Discussion}

The characterized transformers show typical performance values for small 20-30 VA power rating single-phase transformers. From manufacturer datasheets, the typical efficiency for a 30 VA rated power transformer is in the range of 83 [14]-81\% [15], which decreases to $77 \%$ [14] at 22 VA and to $65 \%$ [14] at $4.5 \mathrm{VA}$. The rated power densities vary 
significantly depending on the design (some designs are fully encased), and are typically in the range of 56 [15]-39 VA/ $\mathrm{kg}$ [14] for $30 \mathrm{VA}$ rated transformers and slightly lower (50 [16]-39 [14] VA/kg) for 20 VA rated transformers. In this study, we obtained an efficiency of $80.5 \%$ for the conventional transformer and $70.1 \%$ for the 3D printed transformer core at steady state temperature. The $10 \%$ reduced overall transformer efficiency can most prominently be attributed to the eddy currents generated in the $170 \%$ thicker laminations of the printed design. The reduced power density of the printed design can be attributed to both a larger degree of assembly defect related air-gaps within the core and the overall lower magnetic saturation of the printed material compared to the Goss textured conventional steel. Both designs are within the range of typical power density values for low power transformers.

The 3D printed core exhibited iron losses of $3.05 \mathrm{~W} / \mathrm{kg}$ at $160 \mathrm{~V}$ transformer energization. Analytical calculations identify an average $B_{\max }$ of $1.26 \mathrm{~T}$ at this transformer voltage level. Comparing the magnetizing values with previously measured $3 \mathrm{D}$ printed material magnetization curves, its shearing is proposed. Due to the air-gaps in the assembled printed design, more magnetizing current is required for the same material polarization and voltage generated by the transformer. Similar iron loss values have been measured by Plotkowski et al. for a 3D printed E-type transformer core [17]. In their work, they achieved a core loss of $3.5 \mathrm{~W} / \mathrm{kg}\left(\mathrm{W}_{10,60}\right)$ at $1.0 \mathrm{~T}, 60 \mathrm{~Hz}$ magnetization for a printed $3 \%$ silicon steel lamination inspired core. They achieved considerably improved losses with more complex geometry, reaching approximately $1.5 \mathrm{~W} / \mathrm{kg}\left(\mathrm{W}_{10,60}\right)$ to $3.2 \mathrm{~W} / \mathrm{kg}\left(\mathrm{W}_{15,60}\right)$ with 'Hilbert pattern' $6 \%$ silicon steel. It is important to note, however, that in their work approximately $56 \%$ core fill factor was achieved, resulting in low power density and voltage generation of the transformer.

Further optimization of both the component topology and its material properties are unavoidable for achieving high performance 3D printed transformer cores. To obtain high magnetic polarization (high power density) of the printed material with minimal magnetomotive force, a higher degree of control of the printed material grain structure must be achieved. The effect of the grain structure orientation in relation to the magnetic field is significant as illustrated by Figure 12 [18]. In conventional stampings, the grainoriented pronounced Goss texture can be achieved with various hot and cold rolling stages of the steel sheets. In printed material, the optimization of the material grain structure is largely immature, with some grain structure evolution observed in [13], in heat treated laser-remelted printed silicon steel samples.

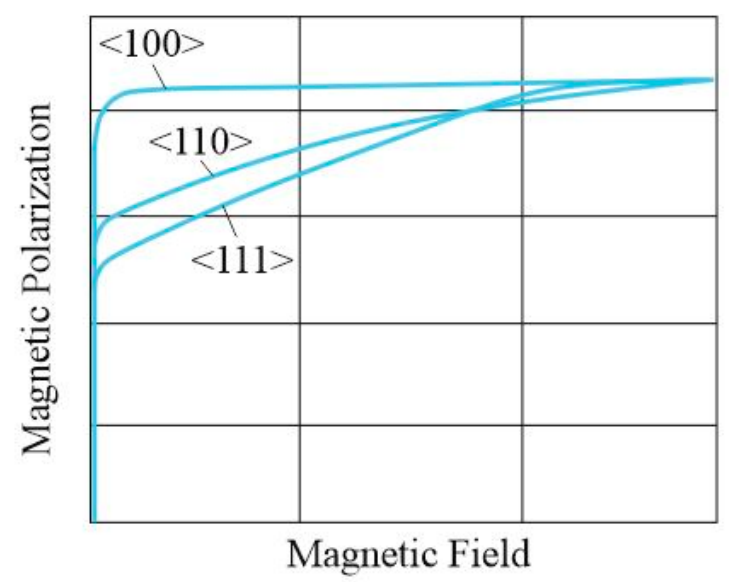

Figure 12. Polarization of the magnetic grains oriented in easy $\langle 100\rangle$, medium $\langle 110\rangle$, and hard $<111>$ magnetization axis direction in relation to the magnetic field (in arbitrary units).

Several topological improvements can be applied to the transformer for enhanced performance. The printed transformer topology can be improved by increasing the fill factor of the assembled components, optimizing the lamination thickness for reduced eddy 
current loss, and increasing its power density through shape optimization for achieving uniform magnetization. Due to the limited multi-material printing capacity of current SLM systems, two methods are proposed for eddy current reduction: the interlocking and the gapped core designs. With next-generation powder deposition methods [19], multiple metal or intermetallic materials can be utilized in parallel, allowing for more options and more advanced core topologies.

First, for increasing the fill factor, higher accuracy of the printing system must be achieved. With the current settings, the printed parts still suffer from low surface roughnessrelated reduced fill factor for interlocking designs or inter-lamination short-circuits and sintered unremovable powder for the gapped designs. Secondly, the lamination thickness can be optimized to provide minimal core losses with maximum part fill factor, i.e., to achieve the optimal ratio of air gap to lamination width. Thirdly, the shape of the core can be optimized for achieving uniform magnetization, weight reduction and improved thermal capacity. Several methods for improving ferromagnetic part performance through topology optimization are discussed in further detail in $[20,21]$. For improved heat exchange of the printed transformer, enhanced convective heat transfer can easily be obtained by increasing its outer surface area with different surface relief structures [22].

\section{Conclusions}

In this paper, a fully functioning, additively manufactured soft magnetic transformer core was fabricated and tested. For the first time in literature, an electromagnetic device with a fully 3D printed magnetic core was evaluated in terms of efficiency and performance. The prototype core showed uncompetitive performance when compared to modern conventional transformer cores. Although the printed material is not currently suitable for the production of commercial transformer cores, the analysis of the prototype core did allow us to demonstrate the current state of the art, identify the technical challenges involved, and propose next steps for realizing topology optimized 3D printing soft ferromagnetic components.

A novel, interlocking core design was developed and utilized successfully for achieving a relatively high fill factor of $89 \%$ (compared to other 3D printed cores) and eddy current reduction of the additively manufactured transformer core. For obtaining higher fill factor with this method, lower surface roughness of the printed parts must be obtained for more precise fitting of the components. Furthermore, the interlocking core design enabled the integration of modular winding to the transformer design, simplifying its assembly process.

The first prototype transformer core showed both lower efficiency (10\% reduced) and power density (34\% reduced), when compared to the conventional modern transformer at their respective optimal working conditions. These preliminary performance results of the first prototype core are likely to improve with more refined core designs and materials as part of future research. Currently, the main challenge in realizing high-performance $3 \mathrm{D}$ printed soft magnetic components is achieving a higher degree of control over the printed material grain texture, since the conventional post-processing methods for Goss textured silicon steel sheets are not suitable for processing geometrically complex 3D printed magnetic components. Even so, for non-grain-oriented applications (such as rotating electrical machines), the current material properties appear suitable, especially with the unprecedented prototyping freedom of 3D printing systems - which could enable the emergence of entirely new types of machines. Although the current 3D printed cores for AC applications suffer either from high eddy current losses or low filling factor, nextgeneration emerging multi-metal SLM printers can potentially improve the additively manufactured core performance considerably. Future work on this project will include further optimization of both the printed material and component topology for designing and constructing AM topology optimized electrical machines. 
Author Contributions: Conceptualization: A.K. and H.T; methodology: A.R.; validation, A.K.; investigation, H.T. and P.S.G.; resources, P.S.G.; writing-original draft preparation, H.T.; writingreview and editing, H.T. and A.K.; supervision, A.K. and A.B.; project administration, T.V.; funding acquisition, A.K. All authors have read and agreed to the published version of the manuscript.

Funding: This research work has been supported by the Estonian Ministry of Education and Research (Project PSG-137).

Institutional Review Board Statement: Not applicable.

Informed Consent Statement: Not applicable.

Data Availability Statement: Data is contained within the article.

Acknowledgments: The authors would like to thank Balti Transformers Ltd. for cooperation.

Conflicts of Interest: The authors declare no conflict of interests.

\section{References}

1. How 3D Printing is Redefining Inductor Coil Production /GKN Additive. Available online: https://www.gknpm.com/en/ourbusinesses/gkn-additive/how-3d-printing-is-redefining-inductor-coil-production/ (accessed on 26 November 2020).

2. GE Aviation 3D Prints 30,000th Metal 3D Printed Fuel Nozzle at Auburn, Alabama Plant. Available online: https: / /3dprint.com/226703/ge-aviation-fuel-nozzle-3d-printed-30000/?fbclid=IwAR38NO-0dAf2BwIkXhVtlC18gAimKnQUSy5 KRv-u08InfruK5Z17Q11P1HI (accessed on 26 November 2020).

3. Conflux Technology is Reinventing Heat Exchangers with 3D Printing » 3D Printing Media Network-The Pulse of the AM Industry. Available online: https:/ / www.3dprintingmedia.network/conflux-technology-reinventing-heat-exchangers / (accessed on 26 November 2020).

4. Ngo, T.D.; Kashani, A.; Imbalzano, G.; Nguyen, K.T.Q.; Hui, D. Additive manufacturing (3D printing): A review of materials, methods, applications and challenges. Compos. Part B Eng. 2018, 143, 172-196. [CrossRef]

5. Tiismus, H.; Kallaste, A.; Belahcen, A.; Rassolkin, A.; Vaimann, T. Challenges of Additive Manufacturing of Electrical Machines. In Proceedings of the 2019 IEEE 12th International Symposium on Diagnostics for Electrical Machines, Power Electronics and Drives (SDEMPED), Toulouse, France, 27-30 August 2019; pp. 44-48. [CrossRef]

6. Tiismus, H.; Kallaste, A.; Belahcen, A.; Tarraste, M.; Vaimann, T.; Rassõlkin, A.; Asad, B.; Ghahfarokhi, P.S. AC Magnetic Loss Reduction of SLM Processed Fe-Si for Additive Manufacturing of Electrical Machines. Energies 2021, 14, 1241. [CrossRef]

7. Stornelli, G.; Faba, A.; Di Schino, A.; Folgarait, P.; Ridolfi, M.R.; Cardelli, E.; Montanari, R. Properties of additively manufactured electric steel powder cores with increased si content. Materials 2021, 14, 1489. [CrossRef] [PubMed]

8. Yap, C.Y.; Chua, C.K.; Dong, Z.; Liu, Z.H.; Zhang, D.Q.; Loh, L.E.; Sing, S.L. Review of selective laser melting: Materials and applications. Appl. Phys. Rev. 2015, 2, 041101. [CrossRef]

9. Li, R.; Liu, J.; Shi, Y.; Wang, L.; Jiang, W. Balling behavior of stainless steel and nickel powder during selective laser melting process. Int. J. Adv. Manuf. Technol. 2012, 59, 1025-1035. [CrossRef]

10. Waasner Magnetic and Technological Properties. Available online: http://www.waasner.de/fileadmin/Assets/PDFs/ MaterialCharacteristics_201111.pdf (accessed on 1 March 2021).

11. Waasner Material Characterization. Available online: http://www.waasner.de/fileadmin/Assets/PDFs/MaterialCharacteristics_ 201111.pdf (accessed on 1 March 2021).

12. Data Sheet Isovac 235-35 A. Available online: https://www.voestalpine.com/division_stahl/content/download/39689/456867 /file/DB_isovac_235-35A_E_281015.pdf (accessed on 1 March 2021).

13. Tiismus, H.; Kallaste, A.; Belahcen, A.; Vaimann, T.; Rassõlkin, A.; Lukichev, D. Hysteresis Measurements and Numerical Losses Segregation of Additively Manufactured Silicon Steel for 3D Printing Electrical Machines. Appl. Sci. 2020, 10, 6515. [CrossRef]

14. Block-PCB Transformers. Available online: http://www.farnell.com/datasheets/1897307.pdf (accessed on 1 March 2021).

15. Block-FL 30/12 Safety Isolating Transformer. Available online: https://www.block.eu/en_US/productversion/fl-3012/ (accessed on 1 March 2021).

16. Brownsburg Electronic Inc. Transformers and Inductors. Available online: http:/ /www.bei.net/PDF/catalogue2004.pdf (accessed on 1 March 2021).

17. Plotkowski, A.; Carver, K.; List, F.; Pries, J.; Li, Z.; Rossy, A.M.; Leonard, D. Design and performance of an additively manufactured high-Si transformer core. Mater. Des. 2020, 194, 108894. [CrossRef]

18. Suwas, S.; Ray, R.K. Crystallographic Texture of Materials; Springer: London, UK, 2014.

19. Aconity Additive Manufacturing. Available online: https://aconity3d.com/ (accessed on 29 March 2021).

20. Andriushchenko, E.; Kallaste, A.; Belahcen, A.; Vaimann, T.; Rassõlkin, A.; Heidari, H.; Tiismus, H. Optimization of a 3D-Printed Permanent Magnet Coupling Using Genetic Algorithm and Taguchi Method. Electronics 2021, 10, 494. [CrossRef] 
21. Orosz, T.; Rassõlkin, A.; Kallaste, A.; Arsénio, P.; Pánek, D.; Kaska, J.; Karban, P. Robust Design Optimization and Emerging Technologies for Electrical Machines: Challenges and Open Problems. Appl. Sci. 2020, 10, 6653. [CrossRef]

22. Ghahfarokhi, P.S.; Podgornovs, A.; Kallaste, A.; Cardoso, A.J.M.; Belahcen, A.; Vaimann, T.; Tiismus, H.; Asad, B. Opportunities and Challenges of Utilizing Additive Manufacturing Approaches in Thermal Management of Electrical Machines. IEEE Access 2021, 9, 36368-36381. [CrossRef] 